\title{
Comparison of Clinical Characteristics According to the Existence of Secondary appendicitis in Pediatric Acute Gastroenteritis: A Retrospective Single Center study
}

Soyoon Choi ( $\nabla$ dimplech@naver.com )

Research article

Keywords: Gastroenteritis, Appendicitis, Child

Posted Date: June 3rd, 2020

DOl: https://doi.org/10.21203/rs.3.rs-30805/v1

License: (c) (1) This work is licensed under a Creative Commons Attribution 4.0 International License. Read Full License 


\section{Abstract \\ Background}

In patients with acute gastroenteritis, radiologic findings are sometimes accompanied by secondary inflammation of the appendix. The purpose of this study was to evaluate the clinical features of acute gastroenteritis with secondary inflammation of the appendix.

\section{Methods}

Medical records from patients who underwent abdominal ultrasonography or computed tomography among those admitted for acute gastroenteritis at Haeundae Paik Hospital from June 2017 to May 2019 were retrospectively reviewed. Clinical features were compared by distinguishing patients with inflammation of the appendix from those without, based on their symptoms and laboratory findings.

\section{Results}

Of the 165 patients, $12(7.3 \%)$ had secondary inflammation of the appendix on ultrasonography and/or computed tomography. Patients with secondary inflammation of the appendix were significantly older than those without (11.7 vs 6.1 years, $p=0.011)$ and more frequently had fever $(83.3 \%$ vs $49.0 \%, p=$ 0.033 ), and high values of C-reactive protein ( $5.38 \mathrm{vs} 0.32 \mathrm{mg} / \mathrm{dl}, \mathrm{p}<0.001)$. The proportion of viral pathogens was higher in patients without secondary appendicitis ( $0 \%$ vs $40.7 \%, p=0.012)$, and the proportion of bacterial pathogens was higher in patients with secondary inflammation of the appendix $(60 \%$ vs $15.1 \%, p=0.004)$.

\section{Conclusions}

Patients with acute gastroenteritis accompanied by secondary appendicitis more commonly have fever, higher C-reactive protein levels, higher bacterial pathogen detection rates, and longer hospital stays. Treatment equivalent to that of bacterial infection is required for patients with secondary appendicitis, and that their symptoms should be closely and continuously monitored and followed-up.

\section{Background}

Acute gastroenteritis, a disease characterized by inflammation of the small colon and colon, is commonly encountered in pediatrics. Most cases are diagnosed through history assessment and physical examination without special testing needed. Most patients improve with symptomatic treatment, including fluid resuscitation and supplemental nutrition. However, when a patient shows severe or prolonged clinical symptoms, the site of pain is the right lower quadrant, or if there are signs of peritoneal irritation, the condition must be differentiated from others that may show similar clinical symptoms, 
particularly acute appendicitis, mesenteric lymphadenitis, appendiceal diverticulitis, and chronic inflammatory bowel disease; this is done using radiologic testing. ${ }^{(1)}$ Radiologic tests (abdominal computed tomography [CT] or abdominal ultrasound [US]) sometimes reveal secondary appendicitis in addition to inflammation in the small and large intestines. Secondary appendicitis refers to inflammation of the appendix resulting from lesions in colonic or periappendiceal sites.

Although acute gastroenteritis is relatively common in children, the clinical features and prognosis of acute gastroenteritis according to the presence of secondary appendicitis have rarely been studied or reported. ${ }^{(2,3)}$ Whether the two disease entities should be classified into a single category or should be considered independent categories with distinct treatment approaches remains controversial. Therefore, in the present study, we compared the clinical features and courses of acute gastroenteritis according to the presence of secondary appendicitis.

\section{Methods}

\section{Patients and Study Design}

Medical records of pediatric patients aged 18 years or younger who received inpatient treatment for acute gastroenteritis at the Inje University Haeundae Paik Hospital between June 2017 and June 2019 were retrospectively analyzed.

Among the patients presenting with inflamed small and large intestines upon radiologic testing (abdominal US or abdominal CT), those with normal appendices were classified as the control group, and those with inflamed appendices were classified as the study group. We recorded the following patient information: sex, age at diagnosis, blood tests (white blood cell [WBC], C-reactive protein [CRP], erythrocyte sedimentation rate [ESR], albumin, hemoglobin, amylase, lipase, aspartate aminotransferase [AST], and alanine aminotransferase [ALT]), stool tests (using stool polymerase chain reaction [PCR]), length of hospital stay, duration of nil per oral (NPO) status, use of antibiotics, complications (e.g., acute kidney injury and hemolytic uremic syndrome), and surgery.

The sensitivity and specificity of appendicitis diagnosis were $100 \%$ and $68 \%$, respectively, using a maximal outer diameter (MOD) cutoff of $6 \mathrm{~mm}$ and $94 \%$ and $88 \%$, respectively, using a cutoff value of $7 \mathrm{~mm} .{ }^{(4)}$ The MOD of the appendix was measured in the transverse plane, where the distance from one outer wall to the opposite outer wall of $6 \mathrm{~mm}$ or less was considered normal, and a MOD of $7 \mathrm{~mm}$ or higher was considered appendicitis. When the MOD was between $6 \mathrm{~mm}$ and $7 \mathrm{~mm}$, color Doppler imaging was performed, and appendicitis was diagnosed based on findings indicating hyperemia. ${ }^{(5)}$ We also measured bowel wall thickness: a thickness of $2 \mathrm{~mm}$ or higher was considered thickening. Appendiceal wall thickness was defined as the distance from the inner mucosal layer to the serosal layer, where a distance of $3 \mathrm{~mm}$ or higher considered appendicitis. ${ }^{(6,7)}$ 
Stool samples were tested for five viruses (group A rotavirus, enteric adenovirus, norovirus GI/GII, and astrovirus) and ten bacteria (Salmonella spp., Shigella spp., Vibrio spp., Campylobacter spp., Clostridium difficile toxin B (CDB), Clostridium perfringens, Yersinia enterocolitica, Aeromonas spp., Escherichia coli 0157:H7, and verocytotoxin-producing E. coli (VTEC)) using Seeplex ${ }^{\circledR}$ Diarrhea ACE detection kits (Seegene, Seoul, Korea), which utilize multiplex PCR. Positive samples were analyzed.

\section{Statistical Analysis}

The data were expressed as frequency with percentage for categorical variables and median with range for continuous variables. Differences in study participants' characteristics were compared across subgroups using the chi-square test or Fisher's exact test for categorical variables and the independent ttest or Mann-Whitney's $U$ test for continuous variables as appropriate. To check for normal distribution, we used the Shapiro-Wilk test. All statistical analyses were carried out using SPSS 24.0, and p-values less than 0.05 were considered statistically significant.

\section{Ethics Statement}

This study was approved by the Institutional Review Board of Haeundae Paik Hospital and was conducted in accordance with the Declaration of Helsinki (Approval No. 2019-10-068-001). As a retrospective study of patients undergoing stool and blood tests, the IRB approved waiving informed consent from patients.

\section{Results}

\section{Age And Sex Distribution (Table 1)}


Table 1

Age and sex distribution

\begin{tabular}{|c|c|c|c|c|c|c|c|}
\hline & \multicolumn{3}{|c|}{$\begin{array}{l}\text { With secondary appendicitis } \\
(n=12)\end{array}$} & \multicolumn{3}{|c|}{$\begin{array}{l}\text { Without secondary appendicitis } \\
(n=153)\end{array}$} & $\begin{array}{l}\mathrm{P} \text { - } \\
\text { value }\end{array}$ \\
\hline $\begin{array}{l}\text { Sex (male, } \\
\% \text { ) }\end{array}$ & \multicolumn{3}{|l|}{$9(75 \%)$} & \multicolumn{3}{|l|}{$80(52.3 \%)$} & $0.146^{1}$ \\
\hline $\begin{array}{l}\text { Age } \\
\text { (months) }\end{array}$ & \multicolumn{3}{|c|}{$141(82-203)$} & \multicolumn{3}{|l|}{$73(1-215)$} & $0.011^{2}$ \\
\hline Age (month) & Male & Female & total & Male & Female & total & \\
\hline$<12$ & $0(0.0 \%)$ & $0(0.0 \%)$ & $0(0.0 \%)$ & $\begin{array}{l}16 \\
(10.5 \%)\end{array}$ & $9(5.9 \%)$ & $\begin{array}{l}25 \\
(16.3 \%)\end{array}$ & \\
\hline $13-72$ & $0(0.0 \%)$ & $0(0.0 \%)$ & $0(0.0 \%)$ & $\begin{array}{l}27 \\
(17.6 \%)\end{array}$ & $\begin{array}{l}24 \\
(15.7 \%)\end{array}$ & $\begin{array}{l}51 \\
(33.3 \%)\end{array}$ & \\
\hline $73-120$ & $\begin{array}{l}3 \\
(25.0 \%)\end{array}$ & $1(8.3 \%)$ & $4(33.3 \%)$ & $14(9.2 \%)$ & $8(5.2 \%)$ & $\begin{array}{l}22 \\
(14.4 \%)\end{array}$ & \\
\hline $121-$ & $\begin{array}{l}6 \\
(50.0 \%)\end{array}$ & $\begin{array}{l}2 \\
(16.7 \%)\end{array}$ & $8(66.7 \%)$ & $\begin{array}{l}23 \\
(15.0 \%)\end{array}$ & $\begin{array}{l}32 \\
(20.9 \%)\end{array}$ & $\begin{array}{l}55 \\
(35.9 \%)\end{array}$ & \\
\hline Total & $\begin{array}{l}9 \\
(75.0 \%)\end{array}$ & $\begin{array}{l}3 \\
(25.0 \%)\end{array}$ & $\begin{array}{l}12 \\
(100.0 \%)\end{array}$ & $\begin{array}{l}80 \\
(52.3 \%)\end{array}$ & $\begin{array}{l}73 \\
(47.7 \%)\end{array}$ & $\begin{array}{l}153 \\
(100 \%)\end{array}$ & \\
\hline \multicolumn{8}{|c|}{ Values are either frequency with percentage in parentheses or median with range } \\
\hline \multicolumn{8}{|c|}{${ }^{1}$ P-values were derived from the Chi-square test. } \\
\hline \multicolumn{8}{|c|}{${ }^{2}$ P-values were derived from the Mann-Whitney's $U$ test. } \\
\hline Shapiro-Wilk & est was & ployed fo & st of norn & assumpt & & & \\
\hline
\end{tabular}

Of the 642 patients admitted to the pediatric ward at Inje University Haeundae Paik Hospital between June 2017 and June 2019 for acute gastroenteritis, 165 patients underwent radiologic testing, particularly abdominal US or abdominal $\mathrm{CT}$, after excluding infants and patients with underlying conditions. One hundred twenty-six (76.4\%) underwent abdominal US, and 39 (23.6\%) underwent abdominal CT. Twelve of these patients $(7.2 \%)$ had secondary appendicitis, with a male-to-female sex ratio of 3:1 (nine boys, three girls). Ages ranged from 6-17 years. The mean age of patients with secondary appendicitis was 141 months, which was higher than that of the non-secondary appendicitis group $(p=0.011)$.

\section{Symptoms (Table 2)}


Table 2

Comparison of presenting symptom between two groups

\begin{tabular}{|llll|}
\hline Presenting symptom & $\begin{array}{l}\text { With secondary appendicitis } \\
(\mathbf{n = 1 2})\end{array}$ & $\begin{array}{l}\text { Without secondary appendicitis } \\
(\mathbf{n = 1 5 3 )}\end{array}$ & P-value ${ }^{1}$ \\
\hline Abdominal pain & $10(83.3 \%)$ & $90(58.8 \%)$ & $0.128^{2}$ \\
\hline Diarrhea & $8(66.7 \%)$ & $109(71.2 \%)$ & $0.747^{2}$ \\
\hline Vomiting & $4(33.3 \%)$ & $75(49.0 \%)$ & $0.135^{1}$ \\
\hline Fever & $10(83.3 \%)$ & $18(11.8 \%)$ & $0.033^{1}$ \\
\hline Hematochezia & $1(8.3 \%)$ & $1.000^{2}$ \\
\hline Values are frequency with percentage in parentheses. & \\
\hline 1 P-values were derived from the Chi-square test. & & \\
\hline
\end{tabular}

The main symptoms were abdominal pain $(n=10)$, diarrhea $(n=8)$, vomiting $(n=4)$, and fever $(n=10)$, and patients had tenderness in the right lower quadrant. The percentage of patients with fever was significantly greater among those with secondary appendicitis $(p=0.033)$.

\section{Blood Tests (Table 3)}


Table 3

Comparison of blood test results between two groups

\begin{tabular}{|llll|}
\hline Blood test & $\begin{array}{l}\text { With secondary } \\
\text { appendicitis } \\
(\mathbf{n}=12)\end{array}$ & $\begin{array}{l}\text { Without secondary } \\
\text { appendicitis } \\
(\mathbf{n}=153)\end{array}$ & $\begin{array}{c}\text { P- } \\
\text { value }\end{array}$ \\
\hline White blood cell count $\left(/ \mathrm{mm}^{3}\right)$ & $10,790(4,670-20,950)$ & $8,750(2,930-24,470)$ & $0.088^{2}$ \\
\hline Hemoglobin (g/dL) & $13.4(11.8-15.4)$ & $12.9(8.2-18.6)$ & $0.583^{2}$ \\
\hline Platelet (/mm $\left.{ }^{3}\right)$ & $240.5(170-287)$ & $288(96-727)$ & $0.002^{2}$ \\
\hline $\begin{array}{l}\text { Erythrocyte sedimentation rate } \\
\text { (mm/h) }\end{array}$ & $35(7-60)$ & $14(2-70)$ & $0.102^{2}$ \\
\hline C-reactive protein (mg/dL) & $5.38(0.05-20.99)$ & $0.32(0.01-22.07)$ & $0.001^{2}$ \\
\hline Albumin (g/dL) & $4.25(3.3-4.6)$ & $4.4(3.1-5.8)$ & $0.306^{1}$ \\
\hline $\begin{array}{l}\text { Aspartate aminotransferase } \\
\text { (U/L) }\end{array}$ & $27.5(21-140)$ & $32(12-266)$ & $0.915^{2}$ \\
\hline Alanine aminotransferase (U/L) & $16(12-251)$ & $17(6-195)$ & $0.782^{2}$ \\
\hline Amylase (U/L) & $54(26-273)$ & $49(4-159)$ & $0.503^{2}$ \\
\hline Lipase (U/L) & $18(14-53)$ & $18(8-110)$ & $0.622^{2}$ \\
\hline Values are median with range & & & \\
\hline 1 P-values were derived from an independent t-test. & & \\
\hline 2 P-values were derived from the Mann-Whitney's U test. & & \\
\hline Shapiro-Wilk's test was employed for test of normality assumption. & \\
\hline
\end{tabular}

Platelet counts were significantly lower among those in the secondary appendicitis group than in those in the non-secondary appendicitis group $(p=0.002)$. By contrast, CRP levels were significantly higher among those in the secondary appendicitis group than in those in the non-secondary appendicitis group $(p<$ $0.001)$.

\section{Stool Multiplex PCR Tests (Table 4)}


Table 4

Comparison of Multiplex Stool PCR results between two groups

\begin{tabular}{|llll|}
\hline Variable & $\begin{array}{l}\text { With secondary } \\
\text { appendicitis } \\
(\mathbf{n}=10)\end{array}$ & $\begin{array}{l}\text { Without secondary } \\
\text { appendicitis } \\
(\mathbf{n}=86)\end{array}$ & $\begin{array}{l}\text { P- } \\
\text { value }^{\mathbf{1}}\end{array}$ \\
\hline $\begin{array}{l}\text { Pathogen detected by multiplex } \\
\text { PCR test }\end{array}$ & $6 / 10(60.0 \%)$ & $51 / 86(59.3 \%)$ & 0.850 \\
\hline Viral pathogens & $0 / 10(0.0 \%)$ & $37 / 86(43.0 \%)$ & 0.012 \\
\hline Rotavirus & $0(0.0 \%)$ & $10(6.5 \%)$ & 1.000 \\
\hline Norovirus & $0(0.0 \%)$ & $12(7.8 \%)$ & 0.603 \\
\hline Astrovirus & $0(0.0 \%)$ & $4(2.6 \%)$ & 1.000 \\
\hline Enteric adenovirus & $0(0.0 \%)$ & $8(5.2 \%)$ & 1.000 \\
\hline Sapovirus & $0(0.0 \%)$ & $3(2.0 \%)$ & 1.000 \\
\hline Bacterial pathogens & $6 / 10(60.0 \%)$ & $14 / 86(16.2 \%)$ & 0.004 \\
\hline Salmonella spp. & $3(25.0 \%)$ & $3(2.0 \%)$ & 0.005 \\
\hline Shigella spp. & $0(0.0 \%)$ & $0(0.0 \%)$ & - \\
\hline Campylobacter spp. & $2(16.7 \%)$ & $5(3.3 \%)$ & 0.083 \\
\hline E. coli O157:H7 & $0(0.0 \%)$ & $0(0.0 \%)$ & - \\
\hline Clostridium difficile Toxin B & $0(0.0 \%)$ & $5(3.3 \%)$ & 1.000 \\
\hline Clostridium perfringens & $1(8.3 \%)$ & $0(0.0 \%)$ & 0.073 \\
\hline Yersinia enterocolitica & $0(0.0 \%)$ & $0(0.0 \%)$ & - \\
\hline Verotoxic E. coli & $0(0.0 \%)$ & $0(0.0 \%)$ & $1(0.7 \%)$ \\
\hline Aeromonas spp. & $0(0.0 \%)$ & & \\
\hline Values are frequency with percentage & in parentheses. & & \\
\hline P-values were derived from the Fisher's exact test. & & & \\
\hline
\end{tabular}

Three cases of non-typhoidal Salmonella, two cases of Campylobacterspp., and one case of Clostridium perfringens were detected in stool samples from patients with secondary appendicitis. All multiplex PCR tests were negative in the remaining patients. The percentage of patients positive for Salmonella spp. was significantly higher among patients with secondary appendicitis $(p=0.005)$. The percentages of bacterial pathogens such as Salmonella and Campylobacterwere significantly greater among patients with secondary appendicitis, while the percentages of viral pathogens such as norovirus and rotavirus were significantly higher among those without secondary appendicitis. 


\section{Clinical Course}

Length of stay and duration of NPO were significantly longer in the secondary appendicitis group ( 6.5 vs. 4 days, $p=0.002$ ). The use of antibiotics was significantly higher in the secondary appendicitis group $(91.7 \%$ vs. $11.1 \%, p<0.001)$. The numbers of total radiologic tests were also significantly higher in the secondary appendicitis group $(p<0.001)$.

\section{Surgical Treatment}

One patient with secondary appendicitis showed perforation on day 2 of admission and underwent emergency appendectomy with cecectomy. All other patients recovered without complications and were discharged.

\section{Discussion}

The clinical significance of appendicitis secondary to acute gastroenteritis is largely unknown. This study is the first to examine the features of pediatric acute gastroenteritis when accompanied by secondary appendicitis in comparison with those with no secondary appendicitis. The findings will contribute to establishing the direction of clinical treatment.

Most primary appendicitis occurs as a result of a series of events resulting from a blockage in the lining of the appendix caused by feces, proliferation of lymphatic tissues, vegetable or fruit seeds, or parasites, which in turn cause closed loop obstructions with continued mucus secretion into the appendiceal lining, thereby distending it and continuously increasing the intraluminal pressure. ${ }^{(8)}$ Continuous elevation of intraluminal pressure causes occlusion of the appendiceal veins and damages the mucosal barrier, thereby inducing bacterial entry and progressing inflammation. ${ }^{(9)}$ By contrast, secondary appendicitis refers to periappendicitis or serositis caused by colonic or periappendiceal lesions spreading inflammation to periappendiceal areas, as opposed to a blockage of the appendiceal lumen, and this results from sympathetic mural edema. ${ }^{(10)}$ Secondary appendicitis is classified as intrinsic or extrinsic, where intrinsic appendicitis is caused by an inflammation of the cecum or large intestine connected to the appendix (e.g., ischemic colitis, infectious colitis, pseudomembranous colitis), and extrinsic appendicitis is caused by inflammation resulting from a spread of lesion in the surrounding organs, such as the gallbladder, liver, bladder, ovaries, kidney, or terminal ileum (e.g., Crohn's disease, cystitis, cholecystitis, sigmoid diverticulosis). ${ }^{(2,10)}$ In the present study, many cases of appendicitis secondary to acute gastroenteritis were intrinsic cases caused by acute ileocecitis affecting the ileum and cecum around the appendix. Acute gastroenteritis cases in which the inflammation is confined to the ileum and cecum are called ileocecitis, and most of these cases are caused by infection in these areas by bacteria such as Yersinia enterocolitica, Campylobacter jejuni, and Salmonella enteritidis. ${ }^{(11,12)}$ Acute gastroenteritis can be diagnosed based on enlarged ileocecal area and normal appendix, ${ }^{(13)}$ and some cases may show appendiceal infection as well. ${ }^{(14)}$ 
One shortcoming of diagnostic US is that the diagnosis rate may vary according to the proficiency of the examiner, although it is widely used as the primary test owing to the benefits of US. This includes its noninvasive simple nature. The examiner can talk to the patient while performing the study in real time, observing peristalsis and blood flow distribution of the digestive tract. The test can be safely repeated frequently, and there is no risk of irradiation. $(15,16)$ In the present study, US was generally the modality chosen, and abdominal CT was performed in the presence of poor acoustic windows, abdominal obesity, and difficulty of ultrasonography. Generally, secondary appendicitis is distinguished from primary appendicitis according to the patterns of cecal wall thickening. Whereas cecal wall thickening is local, asymmetrical, and irregular in primary appendicitis, it is symmetrical, and regular in secondary appendicitis. ${ }^{(3,17)}$ Appendiceal distention can be observed in both cases; however, appendiceal wall thickening and periappendiceal fat deposition are characteristic findings of primary appendicitis. ${ }^{(12)}$ Color Doppler imaging shows increased blood flow in the thickened appendiceal wall in primary appendicitis, while hyperemia of terminal ileum is characteristic of secondary appendicitis. ${ }^{(18,19)}$ Similarly, we diagnosed cases featuring absence of blockage in appendiceal lumen with the presence of symmetrical and regular cecal and appendiceal wall thickening along with inflamed large and small intestines as secondary appendicitis.

The mean age of patients with secondary appendicitis was 11.75 years, suggesting that appendicitis was more common in older children. The major symptoms upon hospital visit were abdominal pain and fever among those with secondary appendicitis, while diarrhea was the most common symptom among those without secondary appendicitis. A significantly higher percentage of patients with secondary appendicitis had fever. CRP levels were significantly higher among patients with secondary appendicitis compared to those without. These findings suggest that patients with secondary appendicitis may have more severe inflammation and therefore have fever more frequently with higher levels of acute inflammation indicators.

Of patients with secondary appendicitis, Salmonella spp., Campylobacterspp., and C. perfringens were detected in the stool samples of five patients, with no viruses detected. Rotavirus, norovirus, and enteric adenovirus were detected among patients without secondary appendicitis. These findings suggest that patients with secondary appendicitis may be more likely to have been infected with bacteria, and this should be noted when determining treatment approaches.

The lengths of hospital stay were longer, and the use of antibiotics was more common among patients with secondary appendicitis. The use of antibiotics and additional radiologic testing were greater among these patients after initial diagnosis because of the persistence and high severity of symptoms. Most patients showed rapid improvement of symptoms only with symptomatic treatment for acute gastroenteritis, and antibiotics were used for shorter periods in the earlier stages with severe symptoms and unclear diagnoses. Nevertheless, because it was reported that infectious ileocecitis occurred in one out of 11 cases of acute appendicitis, ${ }^{(1)}$ and secondary ileocecitis can develop along with fat inflammation even in progressed acute appendicitis, we believe abdominal CT should be performed in 
cases in which US findings are unclear. In the present study, one patient was initially diagnosed with secondary appendicitis with ileocecitis, and CT taken on day 2 of admission indicated by worsening of symptoms revealed intestinal perforation and peritonitis, for which appendectomy and cecectomy were performed. Early diagnosis is often difficult and delayed in children because they usually complain of nonspecific symptoms in the earlier stages and have less ability to express their describe their symptoms than do adults. Because children have more lymphoid tissue in the mucosal layer of the appendiceal wall, proliferation of these lymphoid tissues caused by inflammation can more easily occlude the appendix. (20-22) Children may show quicker progression of inflammation because of their anatomically thin and sparse fiber tissues in the appendiceal wall. They are also at elevated risk for peritonitis because of weak defense systems that might otherwise minimize inflammation in the abdominal cavity; finally, children also have incomplete epiploic development. ${ }^{(23)}$ As shown in the present study, even if appendicitis secondary to acute gastroenteritis had been initially diagnosed, it is possible to have mistaken ileocecitis secondary to progressed primary appendicitis. Even if the diagnosis is correct, it may progress severely and cause peritonitis. Therefore, it is important to continuously and closely monitor symptoms and to perform additional radiologic testing as necessary.

This study has a few limitations. First, the small sample size limits the generalizability of the clinical presentations. Second, bacterial and viral detection rates using stool PCR were low, at $59.4 \%$. Subsequent studies are required to examine larger sample sizes and to strive to enhance bacterial identification and virus detection using various media in order to illuminate the etiology and clinical course of this disease.

\section{Conclusions}

In conclusion, we found that patients with acute gastroenteritis accompanied by secondary appendicitis more commonly had fever, higher CRP, higher bacterial pathogen detection rates, and longer hospital stays. These findings suggest that treatment equivalent to that of bacterial infection is required for patients with secondary appendicitis, and that their symptoms should be closely and continuously monitored and followed-up.

\section{Abbreviations}

CT

Computed tomography

US

Ultrasound

WBC

White blood cell

CRP

C-reactive protein

ESR

Erythrocyte sedimentation rate 
AST

Aspartate aminotransferase

ALT

Alanine aminotransferase

PCR

Polymerase chain reaction

NPO

Nil per oral [NPO]

MOD

Maximal outer diameter

\section{Declarations}

\section{Acknowledgements}

The researcher would like to thank the clinical trial center of Inje University Haeundae Paik Hospital for supporting by the statistical consultation service. However, the institution did not have any influence on the research and writing.

Disclosure of Interest: None to declare

Funding : None

Author information

Affiliations

Department of Pediatrics, Division of Pediatric Gastroenterology, Haeundae Paik Hospital, Inje University College of Medicine, Busan, Korea

\section{Contributions}

SYC conceived of the study and was involved in the design of the study, and reviewed the article, analysis, report writing, and preparation of the manuscript, read and approved the final manuscript.

\section{Authors' information}

SYC is a pediatrician and an assistant professor of pediatrics at Inje University College of Medicine.

Corresponding author

Correspondence to So Yoon Choi.

Ethics declarations 


\section{Ethics approval and consent to participate}

This study was approved by the Institutional Review Board of Haeundae Paik Hospital and was conducted in accordance with the Declaration of Helsinki (Approval No. 2019-10-068-001). As a retrospective medical record study, informed consent was waived from the patient.

\section{Consent for publication}

Not applicable.

\section{Competing interests}

No potential conflict of interests with respect to the research, authorship and/or publication of this article.

\section{Availability of data and materials}

The datasets used and/or analyzed during the current study are available from the corresponding author on reasonable request.

\section{References}

1. Puylaert JB, Van der Zant FM, Mutsaers JA. Infectious ileocecitis caused by Yersinia, Campylobacter, and Salmonella: clinical, radiological and US findings. European radiology. 1997;7(1):3-9.

2. Nordback I, Matikainen M. Secondary appendicitis-a sign of some other intra-abdominal inflammation. Annales chirurgiae et gynaecologiae. 1985;74(3):134-6.

3. Kwon LM, Lee K, Min SK, Ahn SM, Ha HI, Kim MJ. Ultrasound features of secondary appendicitis in pediatric patients. Ultrasonography (Seoul Korea). 2018;37(3):233-43.

4. Rettenbacher T, Hollerweger A, Macheiner P, Rettenbacher L, Tomaselli F, Schneider B, et al. Outer diameter of the vermiform appendix as a sign of acute appendicitis: evaluation at US. Radiology. 2001;218(3):757-62.

5. Puylaert JB. Acute appendicitis: US evaluation using graded compression. Radiology. 1986;158(2):355-60.

6. Simonovský V. Normal appendix: is there any significant difference in the maximal mural thickness at US between pediatric and adult populations? Radiology. 2002;224(2):333-7.

7. Park NH, Oh HE, Park HJ, Park JY. Ultrasonography of normal and abnormal appendix in children. World J Radiol. 2011;3(4):85-91.

8. Lamps LW. Appendicitis and infections of the appendix. Semin Diagn Pathol. 2004;21(2):86-97.

9. Lamps LW. Infectious causes of appendicitis. Infect Dis Clin N Am. 2010;24(4):995-1018. ix-x.

10. Kessler N, Cyteval C, Gallix B, Lesnik A, Blayac PM, Pujol J, et al. Appendicitis: evaluation of sensitivity, specificity, and predictive values of US, Doppler US, and laboratory findings. Radiology. 2004;230(2):472-8. 
11. Puylaert JB. Ultrasonography of the acute abdomen: gastrointestinal conditions. Radiologic clinics of North America. 2003;41(6):1227-42, vii.

12. Zganjer M, Roic G, Cizmic A, Pajic A. Infectious ileocecitis-appendicitis mimicking syndrome. Bratislavske lekarske listy. 2005;106(6-7):201-2.

13. Quigley AJ, Stafrace S. Ultrasound assessment of acute appendicitis in paediatric patients: methodology and pictorial overview of findings seen. Insights into imaging. 2013;4(6):741-51.

14. Van Noyen R, Selderslaghs R, Bekaert J, Wauters G, Vandepitte J. Bacterial ileocaecitis and appendicitis. Lancet. 1990;336(8713):518.

15. Vignault F, Filiatrault D, Brandt ML, Garel L, Grignon A, Ouimet A. Acute appendicitis in children: evaluation with US. Radiology. 1990;176(2):501-4.

16. Ang A, Chong NK, Daneman A. Pediatric appendicitis in "real-time": the value of sonography in diagnosis and treatment. Pediatr Emerg Care. 2001;17(5):334-40.

17. Horton KM, Corl FM, Fishman EK. CT evaluation of the colon: inflammatory disease. Radiographics: a review publication of the Radiological Society of North America Inc. 2000;20(2):399-418.

18. Pickhardt PJ, Levy AD, Rohrmann CA Jr, Kende Al. Primary neoplasms of the appendix manifesting as acute appendicitis: CT findings with pathologic comparison. Radiology. 2002;224(3):775-81.

19. Rao PM, Wittenberg J, McDowell RK, Rhea JT, Novelline RA. Appendicitis: use of arrowhead sign for diagnosis at CT. Radiology. 1997;202(2):363-6.

20. Slattery LR, Yannitelli SA, Hinton JW. Acute appendicitis; evaluation of factors contributing to the decrease in mortality in a municipal hospital over a 20 year period. Archives of surgery (Chicago, III: 1920). 1950;60(1):31-41.

21. Stone HH, Sanders SL, Martin JD. Jr. Perforated appendicitis in children. Surgery. 1971;69(5):673-9.

22. Yildirim E, Karagülle E, Kirbaş I, Türk E, Hasdoğan B, Tekşam M, et al. Alvarado scores and pain onset in relation to multislice $\mathrm{CT}$ findings in acute appendicitis. Diagnostic and interventional radiology (Ankara. Turkey). 2008;14(1):14-8.

23. Graham JM, Pokorny WJ, Harberg FJ. Acute appendicitis in preschool age children. American journal of surgery. 1980;139(2):247-50. 